\title{
A PROSPECTIVE STUDY OF DRUG UTILIZATION PATTERN OF ANTI-EPILEPTIC DRUGS AND THEIR ADVERSE EFFECTS IN A TERTIARY CARE HOSPITAL
}

\author{
HENRY DANIEL RAJ T., SYLVIA A., CHIDAMBARANATHAN S., NIRMALA P.
}

Post Graduate, Department of Pharmacology, Raja Muthiah Medical College, Annamalai University, Chidambaram, Tamil Nadu, India Email: gladystth@gmail.com

Received: 22 Aug 2017, Revised and Accepted: 13 Oct 2017

\section{ABSTRACT}

Objective: Epilepsy or seizure disorder is a common neurologic disorder in the pediatric age group and occurs with a frequency of 4-6 cases per thousand children. Epilepsy, particularly childhood epilepsy, remains a challenge to treat. The management of epilepsy is primarily based on the use of anti-epileptic drugs. Surgery and diet therapy are the other modes of treating childhood seizures. To get an insight into the utilization pattern of anti-epileptic drugs (AEDs) used in pediatric seizures.

Methods: This prospective, longitudinal study was conducted for a period of 8 months in Paediatric Neurology Department of a tertiary care teaching hospital. The data collected from 50 children at the end of the study, were compiled in a specially designed data form and were analyzed.

Results: The distribution of paediatric seizures was found to be high in male children (62\%) and in the age group of 2 to 5 y ( $46 \%$ ). The majority of the children (70\%) were diagnosed with Generalized Tonic-clonic seizures. Sodium valproate was the commonly prescribed AED in all forms of seizures followed by Carbamazepine (18\%), Phenobarbitone (4\%) and Phenytoin Sodium (4\%). AEDs were mostly prescribed as monotherapy (82\%). Adverse reactions noted during this study was minimal (12\%).

Conclusion: Sodium valproate, a conventional AED still remains the commonly prescribed AED for all types of seizures in children aged 2 to 16 y and also was found to be effective and safe.

Keywords: Drug utilization study (DUS), Anti-Epileptic Drugs (AEDs), Adverse Reactions (AR), Seizure disorder

(c) 2017 The Authors. Published by Innovare Academic Sciences Pvt Ltd. This is an open access article under the CC BY license (http://creativecommons.org/licenses/by/4.0/) DOI: http://dx.doi.org/10.22159/ijcpr.2017v9i6.23427

\section{INTRODUCTION}

Drug utilization study (DUS) is defined as "the marketing, distribution, prescription and use of drugs in a society, with special emphasis on the resulting medical, social and economic consequences" [1]. It is, therefore, a study designed to describe quantitatively and a qualitatively-the population of users of a given drug (or a class of drugs like anti-epileptic drugs) and/or the conditions of use (for eg, indications, duration of treatment, dosage, previous or associated treatments and compliance) [2]. The beginning of DUS can be traced back to the early 1960's. Studies on prescription habits [3] aim to analyze the type of drugs prescribed, their dosing schedule and the adequacy of the prescription for a specific diagnosis. Drug utilization studies are powerful exploratory tools to ascertain the role of drugs in society. They create a sound socio-medical and health economic basis for health care decision making [4]. It is also important to realize that inappropriate use of drugs represents a potential hazard to the patients and an unnecessary expense [5]. This necessitates a periodic review of drug utilization to ensure safe and effective treatment. Drug use is a complex process. The optimal benefit of drug therapy in patient care may not be achieved because of underuse, overuse or misuse of drugs. The pattern of use can explain the extent and profiles of drug use and its trend, quality of use, comparing the use of drugs with national, regional and local guidelines or formularies. Drug utilization study facilitates the rational use of drugs in population. Studies on drug utilization focus on the factors related to prescribing, dispensing, administering of medication, it's beneficial or adverse effects [6]. DUS provides information on prescribing habits in a particular disease like diabetes, hypertension, epilepsy etc. in different parts of the world. This motivates the health care providers to follow an established standard healthcare guidelines. The ultimate purpose of drug utilization studies is to contribute to the optimal quality of drug therapy by identifying, documenting and analyzing problems in drug utilization and monitoring the consequences of intervention [7]. Pharmacoepidemiology is the epidemiological method used to study the clinical use of drugs in populations and it is defined as "The study of the use and effects of drugs in a large number of people" [8] As it assesses drug effects in large heterogeneous populations for longer periods, it makes useful contributions towards knowledge on safety and effectiveness of the drug [9]. Surveillance studies to monitor adverse reactions to drugs, a part of DUS, was developed during the 1960s and it plays an educational role on the prescribers to identify risks and to identify patient groups at special risk [10]. Adverse drug reaction studies can be performed by different epidemiologic methods, like cohort studies, case control studies and post mortality surveillance studies Epilepsy or seizure disorder is a common neurologic disorder in the pediatric age group and occurs with a frequency of 4-6 cases per thousand children [11]. Epilepsy, particularly childhood epilepsy, remains a challenge to treat. The management of epilepsy is primarily based on the use of anti-epileptic drugs. Surgery and diet therapy are the other modes of treating childhood seizures [12]. The antiepileptic drugs are of two categories namely conventional drugs like sodium valproate, carbamazepine, phenobarbitone, phenytoin sodium and newer drugs like topiramate, lamotrigine, oxcarbazepine etc. Adjuvant drugs like benzodiazepines are also used in this treatment. An appropriate AED should possess the following features: 1 . Achieve complete seizure control using a single drug. 2. To use the most appropriate formulation to ensure that the child can take and absorb the medication. 3 .

Economically affordable to the patient. 4. Long-term effects on growth and development of the child and short-term effects on behaviour, intellectual function and pattern of sleep should be taken care of. High prevalence of Pediatrics seizures [13] and the use of a higher number of antiepileptic drugs with the various mechanism of action prompted to select this disorder for drug utilization study.

\section{MATERIALS AND METHODS}

The present study focused on the prescribing pattern of Anti-epileptic drugs (AED's) for various seizures occurring in children aged 2 to $16 \mathrm{y}$, treatment outcomes and associated adverse reactions (ADR). This study was a prospective longitudinal study [14] conducted for a period of $8 \mathrm{mo}$ 
from March to December 2016 among children attending Paediatric neurology outpatient Department of RMMCH, Chidambaram. Prescribing pattern of AED was assessed per WHO indication of drug utilization study. The approval for this study was obtained from Institutional Human ethical committee. Each child had a minimum of 5 to 6 visits during the study period of 8 mo. Cases of Status Epilepticus and children not willing for the study were excluded. Following data were collected and recorded in a specially designed data entry form during each visit. During the study period, the pattern of usage of antiepileptic drugs [AED's] was evaluated based on following tools [2, 14-15].

1. The pattern of drug use among epileptic children defined by age and sex.

2. The relationship between the prescribed medicine and the apparent indications.
3. Type of epilepsy most frequently treated.

4. Utilization pattern of AEDs as Monotherapy and Polytherapy.

The adverse reactions (ADR) of prescribed AEDs during the study period were analyzed on the following criteria $[3,16]$.

1. The incidence and type of adverse drug reaction.

2. The causality relationship of ADR with suspected drug according to Naranjo ADR probability scale.

3. Whether the suspected drug was dropped after the ADR and if any treatment was given for the ADR

4. The drug most commonly causing ADRs,the incidence and type of adverse drug reaction.

Table 1: Shows the demographic characteristics of epileptic children

\begin{tabular}{llll}
\hline Age group in y & Male children n (\%) & Female children n (\%) & All children n (\%) \\
\hline $2-5$ & $15(30 \%)$ & $8(16 \%)$ & $23(46 \%)$ \\
$6-10$ & $12(24 \%)$ & $7(14 \%)$ & $19(38 \%)$ \\
$11-16$ & $4(8 \%)$ & $4(8 \%)$ & $8(16 \%)$ \\
\hline
\end{tabular}

\section{RESULTS}

\section{Legend: 1}

Out of 50 children, 31 were male (62\%) and 19 were female (38\%). Maximum children were between the age group of 2-5 y (46\%). As per table 1 , the incidence of epilepsy was more common among male children (62\%) compared to female children (38\%).

\section{Legend: 2}

Shows, the majority of the children (70\%) suffered from Generalized Tonic-Clonic seizures. Two children had myoclonic seizures $(4 \%)$ and two had absence seizures (4\%). The partial simple type was observed in two children (4\%). Febrile seizures were noted in 9 children $(18 \%)$. Sodium valproate was the most frequently used AED (74\%) in most forms of seizures, both as monotherapy and polytherapy. Carbamazepine (CBZ) $(8 \%)$ and phenytoin sodium $(8 \%)$ were the next most used drugs in GTCS type. Absence seizures were treated with sodium valproate only. Sodium valproate and Carbamazepine was prescribed for myoclonic seizures.

Oxcarbazepine was the only AED used for both cases of Simple partial seizures. The majority of the children with febrile convulsions were treated with clobazam alone (55\%). Clobazam in combination with phenobarbitone and sodium valproate were prescribed for $22 \%$ of febrile convulsions.

Table 2: Shows the type of epilepsy and the prescribed medicine

\begin{tabular}{|c|c|c|}
\hline Type of epilepsy & No. of cases $n(\%)$ & Prescribed medicine-n (\%) \\
\hline \multirow[t]{8}{*}{ Generalized Tonic-clonic } & $35(70 \%)$ & Sodium valproate-26(74.3\%) \\
\hline & & Carbamazepine-2 (5.7\%) \\
\hline & & Sodium valproate+Phenytoin sodium-2(5.7\%) \\
\hline & & Sodium valproate+Carbamazepine-2(5.7\%) \\
\hline & & Sodium valproate+topiramate-1(2.8\%) \\
\hline & & Phenytoin sodium+Phenobarbitone-1(2.8\%) \\
\hline & & Sodium valproate+clobazam \\
\hline & & + Phenytoin sodium-1(2.8\%) \\
\hline \multirow[t]{2}{*}{ Generalized myoclonic } & $2(4 \%)$ & Sodium valproate-1(50\%) \\
\hline & & Carbamazepine-1 (50\%) \\
\hline Generalized Absence & $2(4 \%)$ & Sodium valproate-2 (100\%) \\
\hline Partial simple type & $2(4 \%)$ & Oxcarbamazepine-2 (100\%) \\
\hline \multirow[t]{5}{*}{ Febrile convulsions } & $9(18 \%)$ & Clobazam-5 (55.5\%) \\
\hline & & Sodium valproate-1 (11.1\%) \\
\hline & & Phenobarbitone-1 (11.1\%) \\
\hline & & Clobazam+Sodium valproate-1 (11.1\%) \\
\hline & & Clobazam+Phenobarbitone-1 (11.1\%) \\
\hline
\end{tabular}

Table 3: Shows the utilization pattern of AEDs as monotherapy and polytherapy

\begin{tabular}{lll}
\hline Drug therapy & No. of patients & Percentage \\
\hline Monotherapy & $41(50)$ & $82 \%$ \\
Two drug therapy & $08(50)$ & $16 \%$ \\
Three drug therapy & $01(50)$ & $2 \%$ \\
\hline
\end{tabular}

\section{Legend: 3}

As per table 3, 41 children (82\%) were treated with AEDs as monotherapy and 8 children (16\%) received two drug therapy while one child (2\%) had three drug therapy.

\section{Legend: 4}

Sodium valproate was associated with adverse reactions in 4 children $(80 \%)$ as per table 4 . One adverse reaction was observed in a case treated with phenytoin sodium (20\%). Change of AED was required in two cases $(40 \%)$ treated with sodium valproate. 
Table 4: Shows the observed adverse reactions

\begin{tabular}{|c|c|c|c|c|}
\hline $\begin{array}{l}\text { No. of } \\
\text { patients }\end{array}$ & ADR reported & Suspected drug & $\begin{array}{l}\text { Casuality } \\
\text { relationship }\end{array}$ & $\begin{array}{l}\text { Whether treatment with AED } \\
\text { continued/stopped }\end{array}$ \\
\hline 2 & Hyperactivity & Sodium Valprovate & Possible & Stopped \\
\hline 1 & Behavioural disturbances & Phenytoin & Possible & Stopped \\
\hline 1 & Weight gain & Sodium Valproate & Possible & Continued \\
\hline 1 & Sedation & Sodium Valprovate & Possible & Continued \\
\hline 1 & Oral ulcers & Sodium Valprovate & Possible & Continued \\
\hline
\end{tabular}

\section{DISCUSSION}

The present study shows that major incidence of childhood seizures occurs in male children (62\%) which correlate with the results of previous epidemiological studies conducted in India, Malaysia, and Oman[17-19] except for a study in Pakistan by Aziz et al. [20] who contradicts this picture. It has been scientifically proved that female sex hormones (estrogen and progesterone) affect the threshold of seizures to some extent which leads to the difference [21]. The incidence of epilepsy has a bimodal distribution with a peak in the first decade and a second peak in elderly which is also proven in this study as there is a maximal incidence before $10 \mathrm{y}$ ( $84 \%$ children $<10$ y). The distribution of seizures was found to be high in the 2-5 age group of children (46\%) in this study. DR. O P GHAI, an eminent Paediatrician makes a note in his Textbook "the incidence of epilepsy is high in preschool years" [22] and our study confirmed it. The age distribution has a critical importance in DUS as it gives an idea whether drug treatment varies according to different age groups. Generalised tonic-clonic seizures were the commonest form of seizures (70\%) observed in children between 2-16 y in our study. A majority of previous clinical studies like Shaireen Usman et al. [23] have shown the dominance of this seizure type in children while a study conducted in Coimbatore private hospital in south India [24] contradicts by concluding that Partial seizures were commonly observed (51\%) in children below 16 y. Jincy George and Julia [25] also conclude that $51 \%$ of their pediatric study group were of the general type of epilepsy. Nelson's textbook of pediatrics also says about the dominance of GTCS in children [13]. In our study, other types of generalized seizures were observed in $8 \%$ and Febrile convulsions in $18 \%$ of children. Febrile seizures have been reported to be one of the most common causes of seizure attacks in children. Febrile convulsions are the commonest provoked seizures and 3-5\% of children experience them between 6 mo to 5 years [22]. In our study, all 9 children with febrile seizures had incidence before 3 y of age. Sodium valproate was found to be the most commonly prescribed AED (72\%) as against other conventional AED's like Tegretol (18\%), Phenytoin Sodium (4\%), phenobarbitone $(4 \%)$ in our study. The current NICE guidelines [15] advise either CBZ (partial type) or Sodium valproate (partial or generalized) as the first line of therapy for epilepsy. Hence, the broad usage of Sodium valproate in this study has followed the guidelines. Sodium Valproate was effective with less adverse effects in all forms of seizures except simple partial type where oxcarbazepine was used. Sodium valproate was used as monotherapy (70\%) in the majority of cases. The increase indose of Sodium valproate was required in 4 cases $(16 \%)$ of tonic-clonic seizures. Loscher, 2002 has quoted in his book "Basic Pharmacology of valproate" after a clinical experience with sodium valproate for $35 \mathrm{y}$ in the treatment of Epilepsy [26] that Sodium valproate has a broad spectrum of anticonvulsant activity, although it is primarily used as a first line treatment for Tonic-clonic, absence and myoclonic seizures and used as a second line treatment for partial seizures and infantile spasms. Valproate and phenobarbitone have favorable pharmacokinetics in children, whereas carbamazepine and phenytoin have unfavourable kinetics as per Glauser TA et al. in 2013 [27] Antiepileptic drug utilization and seizure outcome among pediatric patients in a Malaysian hospital in 2010 [18] conclude that valproate was the most commonly used drug (37\%) followed by carbamazepine (28\%). A multicentric study conducted in Bagalkot, Karnataka 2015concludes that conventional AEDs was more effective in terms of reduction of seizures and are mostly used as monotherapy [28]. Phenytoin was the most commonly used AED followed by valproate as per their conclusion which contradicts the results of our study. In 2002,DUS conducted in Oman, Hansens $\mathrm{Y}$ et al. [19] confirms the use of valproate $(49 \%)$ as the commonly prescribed drug followed by CBZ (44\%) Antiepileptic DUS in a Bangladesh medical college hospital in 2013concludes that the use of older AED's like valproate, CBZ, phenytoin, and phenobarbitone is a very cost-effective therapy in primary healthcare settings [29]. Valproate was also the only drug supplied free of cost during the study period in RMMCH pharmacy and this also could have been a reason for its wide use in prescriptions for seizures, as it mainly contributes in increasing the compliance of patients. Prophylaxis for the recurrence of Febrile seizures in children may be continuous or intermittent. Oral diazepam, clobazam, and midazolam are effective prophylactics in intermittent type and Sodium valproate, Phenobarbitone is effective in continuous therapy [13] in our study, the above protocols were accurately followed. Clobazam was prescribed in 5 children as monotherapy (55.5\%) while Sodium valproate and Phenobarbitone were prescribed as monotherapy in 2 children $(22.2 \%)$. Two drug therapy in combination with clobazam were prescribed in $22.2 \%$ of febrile convulsions. In this clinical study, topiramate and oxcarbazepine were the only newer AED's used which was, in contrast, to study by Maity and Gangadaran's[30] where Lamotrigine was the commonly used newer AED. Controlling seizures with minimal adverse effects and maintaining the patient's ability to perform daily activities are the critical measures of treatment outcome. In our study, 43 [86\%] children had complete control of seizures during the study period. The increase in dosage of the same AED was required in 5 children (10\%). Change of AED was required in 2 children (4\%). Sodium valproate was the drug responsible for ADR's in 5 cases and phenobarbitone for a single case. All the reactions were not serious warranting treatment and the relationship were possible to the drugs in all cases. Two cases of congenital hypothyroidism along with seizure disorder developed hyperactivity during their treatment with sodium valproate and were switched over to Carbamazepine, which proved fruitful No serious drug-specific adverse reactions were noted during this study. For example, Hepatotoxicity of Sodium valproate was assessed during this study period by conducting Liver function tests regularly in all children receiving this drug. Alterations in the values of the liver function tests could not be appreciated.

\section{CONCLUSION}

Sodium valproate, one among the conventional AEDs still remains the mainstay of treatment in pediatric seizures. Sodium valproate can be used as the first-line drug in all forms of generalized seizures and as a continuous prophylactic in febrile seizures. Side effects were minimal and Compliance was good in most of the children. Monotherapy was followed mostly in the treatment of pediatric seizures. There was a rational prescription of AEDs in all children. This drug utilization study in pediatric neurology department gives an insight into current pharmacotherapy practices in childhood seizures. Limitations are data from an OP department with a small sample size. Hence, the findings cannot be generalized. Moreover, children enrolled in this study could not be followed up for the occurrence of long-term adverse reactions or occurrence of drugdrug interactions. Further such studies with large sample size in pediatric seizures would guide clinicians toward rational drug prescribing which an ultimate aim of drug utilization studies is.

\section{ACKNOWLEDGEMENT}

I am thankful to the Professors of the Department of Pharmacology, Raja Muthiah Institute of Medical Sciences and co-post graduates for their inspiration to take up this study and they guided me through 
each and every step of this Research work, by giving useful suggestions and made me complete this work successfully. I am also thankful for my co-guide from the Department of Paediatrics in guiding me through every step of this research.

\section{CONFLICT OF INTERESTS}

\section{Declared none}

\section{REFERENCES}

1. WHO expert committee the selection of essential drugs. Technical report series 615, WHO, Geneva; 1977.

2. Pharmacoepidemiology: an introduction. $3^{\text {rd }}$ edition. edited by Hartzena AG, Porta M, Tilson HH. Cincinnati Harvey Whitney books; 1998.

3. Dukes MNG. Introduction in DUS: Methods and uses: Edited by Dukes MNG, WHO Regional Publications, European series; 1992. p. 1-4.

4. Capella D. Descriptive tools and analysis in DUS: Methods and uses: Edited by Dukes MNG; 1992. p. 55-78.

5. Bakassi, Lunde PKM. National drug policies: the need for drug utilization studies. Trends Pharmacol Sci 1986; 7:331-4.

6. Nehru, Kohli K, Kapoor, Sharma. Drug utilization study in outpatient department in Jammu medical college. JK Science 2005; 7:149-51.

7. Hawkey CJ, Hodgson S, Norman A. Effect of reactive pharmacy intervention on quality prescribing. Br Med J 1990;300:986-90.

8. Ilse truther. A review of drug utilization and methodologies. Jordon J Pharm Sci 2008;1:2.

9. Lunde PK, Bakaas I. Epidemiology of drug utilization basic concepts and methodology. Acta Med Scand 1988; Suppl 721:7-11.

10. Strom BL, Stephen EK. Pharmacoepidemiology. $4^{\text {the }}$. John Wiley and Sons, England; 2005.

11. Sjoqvist F, Birkett D. Drug utilization: Introduction to drug utilization research. WHO publications; 2003. p. 76-84.

12. MNG Dukes. Drug utilization studies. Methods and uses. WHO regional publications. European series; 1993. p. 1-193.

13. Seizures in childhood/Nelson's textbook of paediatrics; 2011. p. 1686-7.

14. Serradil J, Bjornson DC, Hartzema AG. Drug utilization study methodologies: national and international perspectives. Drug Intell Clin Pharm 1987:21:994-1001.

15. National Institute for Health Clinical Excellence (NICE) Clinical guidelines 137. The Epilepsies: the diagnosis and management of Epilepsies in adults and children in primary and secondary care; 2012.

16. CA Naranjo, U Busto, EM Sellers, P Sandor, I Ruiz. Clinical pharmacology and therapeutic program. New England Med J 1981;30:239-45.

17. Shobana Mathur, Sumana Seu, L Ramesh, Sathish Kumar M. Utilization pattern of antiepileptic drugs and their adverse effects in a teaching hospital. Asian J Pharm Clin Res 2010;3:55-9.

18. Hasan SS, Bahari MB, Babar ZU. Antiepileptic drug utilization and seizure outcome among Malaysian public hospital Singapore. Med J 2010;51:21-7.

19. Hansens Y, Deluxe D, Al Belushi. Drug utilization pattern of antiepileptic drugs in Oman. Jelin Pharm Ther 2002:27:357-61.

20. Aziz H, Akhtar SW, Hasan KZ. Epilepsy in Pakistan and psychosocial problems: A population-based epidemiological study. Epilepsia 1997;38:1069.

21. Mac TL. Epidemiology, etiology, and clinical management of epilepsy in Asia. Lancet Neurol 2001;6:533-43.

22. Ghai Paul Bagga. Essential paediatrics. Chapter 17. Vol. 7. 2013. p. $529-35$

23. Shaireen Usman, Dilli Ram Kafle, Krishna Kumar Oli. Clinical profile of patients with Epilepsy. J Nobel Med College 2014;3:1-4.

24. Chitra Bhajan, Parshava R Mehta, Nissey K Sunny. A study on drug utilization pattern of antiepileptics in paediatrics at a private corporate hospital in Coimbatore, SouthIndia: World J Pharm Pharm Sci 2017;6:542-9.

25. Jincy George, Julia Jose, Divya Ashok Kulkarni, Ramesh Rajesh Poi. Evaluation of drug utilization and analysis of AEDs at tertiary care hospital. Indian J Pharm Practice 2016;9:189-94

26. Loscher. Basic pharmacology of valproate-a review after $35 \mathrm{y}$ of clinical uses for the treatment of epilepsy. CNS Drugs 2002;16:669-74.

27. Glauser TA, Buchhalter JR. Management of childhood epilepsy. Continuum (Minneap Minn) 2013:19;656-81.

28. Krithika M Bhatt, Supriya D Malhotra, Kamlesh P Patel. Drug utilization in pediatric neurology outpatient department in India. J Basic Clin Pharmacol 2014;5:68-73.

29. Mansur Habib, Sharif Uddin Khan, Mohd Azhakul Hoque. Antiepileptic drug utilization in Dhaka Medical College Hospital, Bangladesh. Asian J Pharm 2010;6:575-8.

30. Maity N, Gangadhar N. Trends in the utilization of AEDs, among pediatric patients in a tertiary care hospital. Curr Neurobiol 2011;2:117-23. 